\title{
Should a reversible, but lethal, incident not be treated when a patient has a do-not-resuscitate order?
}

\author{
Philip C. Hébert MD PhD, Debbie Selby MD
}

Competing interests: None declared.

This article has been peer reviewed.

Correspondence to:

Philip Hébert,

philip.hebert@sunnybrook.ca

CMAJ 2014. DOI:10.1503 /cmaj.111772
$\mathrm{D}$ espite the frequency of use of do-notresuscitate orders, there is still uncertainty regarding their optimal use. We discuss a controversial issue concerning end-oflife care arising from two cases from the Office of the Chief Coroner for Ontario: What are the limits of medical therapy for patients who have a critical incident and for whom a do-not-resuscitate order has already been written?

\section{Cases}

\section{Case 1}

A 90-year-old woman lived independently, despite a history of stroke, congestive heart failure, emphysema, osteoporosis and hypothyroidism. After a fall in her residence during the winter, she presented to the emergency department of her local hospital where she was given long-acting morphine orally to control pain in her chest wall. With a diagnosis of pneumonia and renal failure, the patient was transferred to a ward, where the morphine was discontinued and hydromorphone was ordered in its place. Unfortunately, the patient received both analgesics. Two days after admission to the ward, she was found unrousable. Narcotic overdose was considered. After a single bolus dose of naloxone intravenously, the patient became alert; however, left alone for a few minutes, she was then found without vital signs. No further attempt at resuscitation was attempted because a do-notresuscitate order had been previously entered in her chart at her request.

\section{- Ker POINTS}

- Do-not-resuscitate orders are common, but their scope and importance can be unclear.

- The exact nature of what such an order entails must be documented.

- Do-not-resuscitate orders should not necessarily prevent the provision of appropriate treatments for unanticipated outcomes of care.

\section{Case 2}

A 42-year-old woman who had received a diagnosis of breast cancer was found to have bony metastases four years later, for which she underwent hormonal treatment in conjunction with chemotherapy and radiotherapy. Esophageal stricture developed, and the patient required bougienage 11 and 12 years after the initial diagnosis. The year after the patient's last bougienage, she was admitted to hospital with dehydration, dysphagia and poorly controlled pain. In the emergency department, she received small doses of morphine intravenously. Upon transfer to the ward, the patient was inadvertently given hydromorphone instead of morphine. Shortly thereafter she was found not breathing. Resuscitation was not performed because of a do-not-resuscitate order on her medical record.

\section{Discussion}

Physicians should be familiar with modern principles of end-of-life and palliative care for patients with terminal illnesses. Many guidelines have been developed and promulgated by professional societies and regulatory authorities. ${ }^{1}$ Central to highquality end-of-life care are the discussions physicians are encouraged to have with the patient and family, or substitute decision-maker, regarding the expected prognosis and the patient's wishes concerning end-of-life care. These discussions are particularly appropriate for patients with chronic illnesses and fragility for whom death would not be an unexpected outcome at any point. ${ }^{2}$

Resuscitation was originally devised for, and is most successful in, those circumstances where death due to cardiac arrest is unexpected and sudden (e.g., a near-drowning, sudden lethal arrhythmia). ${ }^{3}$ Cardiopulmonary resuscitation (CPR) subsequently became the default response in multiple situations unless there was an order precluding its use. However, despite the in- 
creased use of in-hospital CPR, studies have shown little improvement in survival. ${ }^{4}$

At first, do-not-resuscitate orders were not always explicit or openly acknowledged. However, such orders have been used with increasing frequency since their introduction to medicine in the 1970s. ${ }^{5}$ In clinical use, the withholding of resuscitation may be interpreted narrowly or widely. Consistent with many guidelines, the order may imply withholding basic cardiac life support (i.e., chest compressions, manual ventilation) and advanced cardiac life support (i.e., basic support with the addition of intubation, defibrillation, vasopressors and antiarrhythmic agents) while still allowing other appropriate interventions, such as transfusion or surgery. Alternatively, for some clinicians, the order may imply the withholding or the withdrawing of a wider set of treatments, such as antibiotics, antihypertensive agents, anticoagulants, oxygen, surgery, nutrition and fluids.

That the decision not to resuscitate a patient or the presence of a do-not-resuscitate order on a patient's chart is a powerful predictor of death in hospital is not surprising. ${ }^{6}$ Does this trend mean that we are very good at predicting who will die in hospital and thus write do-not-resuscitate orders for patients who are, to paraphrase Hippocrates, overmastered by their illness? Or, more ominously, does a do-not-resuscitate order mean a patient is less assiduously cared for and denied potentially life-prolonging therapies other than CPR ? ${ }^{7}$ Available evidence supports the former view, but the latter interpretation does have some evidence in its favour ${ }^{8}$ and highlights the importance of clear communication between physician, patient and family (if appropriate). ${ }^{9}$

These two cases suggest that there can be confusion as to what a do-not-resuscitate order implies. Each death appears to have had, as its proximate cause, a reversible and common drug error - a narcotic drug overdose leading to respiratory arrest and cardiovascular collapse. This outcome may have been made more likely by the patients' conditions, underlying disease processes and narcotic naïveté. The judgment of the clinicians may have been swayed by the existence of the do-notresuscitate orders, who may have interpreted that it would be wrong to attempt to correct a narcoticinduced cardiorespiratory arrest.

Were the clinicians right to withhold or stop attempting a reversal of the sequence of events resulting from the probable narcotic overdose? The answer to this question is equivocal without more patient information - in particular, better knowledge of the patient's circumstances and wishes (Box 1). ${ }^{10,11}$ Specific discussions focused on the limits of care that the patient wants could help inform such situations. For example, exploring (and documenting) whether patients want potentially reversible conditions treated and, if so, how aggressively, allows patients to identify limits beyond which further treatment would feel too burdensome to them. Patients tend to poorly understand what resuscitation can and cannot do. ${ }^{12}$ To help patients appreciate the benefits and burdens of resuscitation, clinicians must be adept at explaining end-of-life care options in realistic and unbiased ways - neither too optimistically nor too pessimistically. ${ }^{13,14}$

\section{Box 1: Cases revisited}

\section{Palliative care perspective:}

Both cases outline an iatrogenic contribution to death for which an easy and reliable treatment is available. In each case, when the patient had apnea, no attempts at reversal were made in keeping with a pre-existing do-not-resuscitate order. Case 1 is particularly difficult, because the cause for the patient's loss of consciousness was identified. Given the pharmacokinetics of morphine, it was predictable that further doses of naloxone would likely be required, particularly for a patient with renal failure. In case 2 , we do not know if the treating team identified the probable cause of the patient's apnea.

Case 1: Although the patient had previously lived independently and had potentially treatable acute illnesses (pneumonia, renal failure and chest wall pain), her chances of recovery to discharge after an in-hospital arrest were extremely poor. ${ }^{10,11}$ Here, the time between the patient being alert after naloxone was administered and being found without vital signs is critical. If this period was truly no more than two to three minutes, it may well have been reasonable to administer a further dose of naloxone and provide noninvasive short-term ventilation support (e.g., bag-valve-mask ventilation). If, however, more than a few minutes had elapsed, the chances of successful resuscitation leading to hospital discharge with the patient in a physical and cognitive state similar to that on her admission were so slim that following her wish for "no cardiopulmonary resuscitation" seems wisest.

Case 2: By description, the patient was found not breathing after coadministration of morphine and hydromorphone, but no resuscitation attempts were made based on the existing do-not-resuscitate order. Clearly, the patient had advanced disease, but she did not appear to be imminently dying until she was given the two drugs. If the elapsed time between drug administration and discovery of apnea was short (no more than two to three minutes of apnea, as in case 1), a trial of naloxone and noninvasive respiratory support would seem reasonable and would not countermand the order. Successful treatment may well have returned the patient to a setting whereby good palliative care, including pain management and relief of her dysphagia, may have allowed her further time.

\section{Clinical ethics perspective:}

Should critical incidents threatening death be treated if they happen to patients with a do-not-resuscitate order? The answer to this question depends on the circumstances of the individual case, which can help determine the most appropriate response to such an incident.

Case 1: There was some expectation that this patient might have been able to return to her previous level of functioning. If this was so and she was not opposed to limited resuscitative efforts (e.g., treatment of the drug overdose, temporary mechanical or manual ventilation), then naloxone ought to have been continued.

Case 2: It appears that this patient's disease was at a very advanced stage and that her suffering was not easily treated. If her death was truly imminent, resuscitation would likely not have been successful. In such circumstances, the reluctance to treat a drug overdose is understandable. However, lacking patient consent to not intervene in treatable causes of death, the failure to address a readily reversible cause of death would seem less than optimal. 
Not all circumstances can be foreseen; for example, medical errors, such as in these patients' cases, cannot be predicted. However, do-not-resuscitate orders are frequently written without any background rationale in a patient's chart. ${ }^{15}$ This leaves other health care practitioners with the unenviable task of deciding, at the moment of the arrest, just which interventions are not to be provided.

Ideally, a patient's chart would include the concept of "limits of care," detailing where in the spectrum of care - from no treatment or interventions for any illness to full aggressive treatment, including all attempts at life support - the patient's personal goals lie (Box 2). Although the patients in these two cases had consented to a do-notresuscitate order, their charts did not clarify what was to be withheld and under what circumstances.

\section{Conclusion}

Providing proper care at life's end is fraught with challenges. Advance directives for care are important but do not often address the complexities of end-of-life care for the individual patient. Deciding on and documenting patient preferences for the circumstances and circumscription of resuscitation efforts may ameliorate some of these challenges.

\section{Box 2: Suggestions for practice}

- Do-not-resuscitate orders should be considered and discussed as part of an overall end-of-life treatment plan. This plan should address the limits of care and not simply result in a do-not-resuscitate order. ${ }^{16}$

- The benefits and burdens of resuscitation options should be discussed with all patients, especially those with illnesses for whom death would not be a surprise. ${ }^{17}$

- Patients and their families or substitute decision-makers should be helped to understand the nature of, and the differences between, temporarily reversible and irreversible causes of decline and death. ${ }^{18}$

- Reasons for and discussions about do-notresuscitate orders and end-of-life care should be carefully documented in patients' charts. ${ }^{14,16}$

- Where outcomes are unclear or a patient's wishes unknown, it would be prudent for trials of interventions to be considered or instituted until the patient's wishes and interests can be fully reassessed.

\section{References}

1. Decision-making for the end of life. Toronto $(\mathrm{ON})$ : College of Physicians and Surgeons of Ontario; 2006.

2. Lynn J, Adamson D. Living well at the end of life: adapting health care to serious chronic illness in old age. Washington (DC): The Washington Home Center for Palliative Care Studies; 2003. Available: www.medicaring.org/whitepaper/ (accessed 2012 Apr. 16)

3. Kouwenhoven WB, Jude JR, Knickerbocker GG. Closed chest cardiac massage. JAMA 1960;173:1064-7.

4. Ehlenbach WJ, Barnato AE, Curtis JR, et al. Epidemiologic study of in-hospital cardiopulmonary resuscitation in the elderly. N Engl J Med 2009;361:22-31.

5. Burns JP, Edwards J, Johnson J, et al. Do-not-resuscitate orders after 25 years. Crit Care Med 2003;31:1543-50.

6. Shepardson LB, Younger SJ, Speroff T, et al. Increased risk of death in patients with do-not-resuscitate orders. Med Care 1999; 37:727-37.

7. Zahuranec DB, Brown DL, Lisabeth LD, et al. Early care limitations independently predict mortality after intracerebral hemorrhage. Neurology 2007;68:1651-7.

8. Ehlenbach WJ, Barnato AE, Curtis JR, et al. Epidemiologic study of in-hospital cardiopulmonary resuscitation in the elderly. N Engl J Med 2009;361:22-31.

9. Von Gunten CF, Ferris FD, Emanuel LL. Ensuring competency in end-of-life care. JAMA 2000;284:3051-7.

10. Monteleone PP, Lin CM. In-hospital cardiac arrest. Emerg Med Clin North Am 2012;30:25-34.

11. Larkin GL, Copes WS, Mathanson BH, et al. Pre-resuscitation factors associated with mortality in 49,130 cases of in-hospital cardiac arrest: a report from the National Registry for Cardiopulmonary Resuscitation. Resuscitation 2010;81:302-11.

12. Thorevska N, Tilluckdharry L, Ticko S, et al. Patients' understanding of advance directives and cardiopulmonary resuscitation. J Crit Care 2005;1:26-34.

13. Silveira MJ, Kim SY, Langa KM. Advance directives and outcomes of surrogate decision making before death. $N$ Engl J Med 2010;362:1211-8.

14. Frank C, Heyland D, Chen B, et al. Determining the resuscitation preferences of elderly inpatients: a review of the literature. CMAJ 2003;169:795-9.

15. Lo B, Tulsky J. Code status confusion. Agency for Healthcare Quality and Review; 2003. Available: www.webmm.ahrq.gov /case.aspx? caseID=25 (accessed 2012 Apr. 16)

16. Kaldjian LC, Broderick MS. Developing a policy for Do not resuscitate orders within a framework of goals of care. Jt Comm J Qual Patient Saf 2011;37:11-9.

17. von Gunten CF. Discussing do-not-resuscitate status. J Clin Oncol 2001;19:1576-81.

18. Casarett DJ, Quill TE. "I'm not ready for hospice": strategies for timely and effective hospice discussions. Ann Intern Med 2007; 146:443-9.

Affiliations: Department of Family and Community Medicine (Hébert), University of Toronto; and Sunnybrook Health Sciences Centre (Selby), Toronto, Ont.

Contributors: Philip Hébert conceived of the idea for the article and drafted the manuscript. Both authors wrote the manuscript and revised it critically for important intellectual content. Both of the authors approved the final version submitted for publication.

Acknowledgements: These cases were provided by the Patient Safety Review Committee of the Office of the Chief Coroner for Ontario. The authors thank Dr. Dan Cass, Chair of the Patient Safety Review Committee, Office of the Chief Coroner for Ontario, for his editorial assistance in the preparation of this paper and support from the Office of the Chief Coroner for permission to publish. 